\title{
The Role of Transnational NGOs' Activities in Aiding the Rohingya Refugee Crisis in Bangladesh: A Case Study of the Finnish Red Cross
}

\author{
Al Amin \\ University of Eastern Finland
}

\begin{abstract}
In fact, Myanmar's military forces have been deliberately persecuting the Rohingya minority since 1978. In 2017, the Rohingya had to flee Myanmar and, as a result, there was an influx of more than one and half million Rohingya to Bangladesh. The Finnish Red Cross (FRC) had a quick response to the emergency appeal of the International Federation of Red Cross (IFRC) on the behalf of the Rohingya in Bangladesh in 2017.
\end{abstract}

This research paper is to learn how the activities of the FRC affected the Rohingya refugees, what challenges were faced by the staff of the FRC, and what part was played by other contributors in cooperation with the FRC. The research materials include primary and secondary data. I used this data in methodological triangulation in a deductive approach.

From October 2017 to October 2018, 43,780 patients were treated by the RCEH. The main challenges faced by the staff of the FRC was the lack of local infrastructure, lack of internet availability and so on. In contrast, the Inter Sector Coordinator Group (ISCG) and Bangladesh Red Crescent Society were one of the key contributors in attempting to solve these problems, as well as cooperating with the FRC staff, local government, local and international NGOs, and other agencies.

This paper is intended to benefit research on the contribution of international NGOs (INGOs) from a global humanitarian perspective.

Keywords: Finnish Red Cross, Globalization, Rohingya, Transnationalism, TNGOs. 